\title{
Perfil de paisagem entre os municípios de Águas Belas e Saloá (Pernambuco - Brasil), com ênfase na cobertura vegetal
}

\author{
Landscape profile between the municipalities of Águas Belas and Saloá (Pernambuco - \\ Brazil), with emphasis on vegetation cover
}

\author{
Santos $^{1}$, L. S.; Silva ${ }^{12}$, H. P. B.; Pereira ${ }^{1}$, E. C. G.; Cabral ${ }^{1}$, C. J.; Silva ${ }^{1}$, J. C. B. \\ linaldo.geo@gmail.com
}

\begin{abstract}
Resumo
A paisagem semiárida do nordeste brasileiro muitas vezes é descrita como sendo monótona e de baixa diversidade. Contudo, o presente estudo demonstra que através do perfil de paisagem foi possível verificar uma marcante variação na cobertura vegetal, propiciada pela amplitude do gradiente topográfico, e consequente variação climática. Tal variação é traduzida desde uma caatinga típica, portanto mais seca, na porção da Depressão Interplanáltica do Alto Ipanema, passando por uma vegetação de porte mais densa e maior no setor da Cimeira Estrutural Pernambuco-Alagoas, inclusive com a presença de um enclave de cerrado no topo do brejo, município de Saloá. Esta diferenciação de habitats foi comprovada através das análises realizadas em campo, bem como pela identificação de espécies vegetais coletadas na área e levadas para o herbário, sendo possível desta forma, atestar a qual formação pertencia cada espécie.
\end{abstract}

Palavras-chave: Semiárido nordestino; perfil de paisagem; cobertura vegetal.

\begin{abstract}
The semi-arid landscape of Brazilian northeastern is often described as being dull and with low diversity. However, this study shows that through the landscape profile was possible to observe a highlighted variation in vegetation cover, fostered by the breadth of the topographic gradient and consequent climate change. This variation is translated from a typical "caatinga" therefore drier, in the portion of Inter-plateau Depression from High Ipanema, through a denser and larger vegetation in the sector of Structural Summit Pernambuco-Alagoas, in addiction the presence of a closed enclave on top of the marsh, in the city of Saloá. This differentiation of habitats was confirmed by the analyzes carried out in the field, as well as the identification of vegetation species collected in the area and taken to the herbarium, and can thus attest which formation belonged to each species.
\end{abstract}

Keywords: Northeast semi-arid; landscape profile; vegetal cover.

\section{INTRODUÇÃO}

O estudo dos brejos de altitude no Nordeste brasileiro, e mais especificamente em Pernambuco, vem se apresentando cada vez de forma mais intensificada, seja nas Ciências Geográficas e Biológicas, como em áreas afins. Contudo, tal estudo não é recente, autores como Gilberto Osório de Andrade, Raquel Caldas Lins, Dárdano de Andrade Lima e Vasconcelos Sobrinho, ícones das décadas de 60 e 70, já trabalhavam este tema. Com isso, essas áreas de exceção são capazes de proporcionar condições ambientais para que representações de outros biomas se desenvolvam no domínio das caatingas, como é o caso de manchas de cerrado e floresta Atlântica. Os principais estudos fitogeográficos nessas áreas de exceção se direcionam no sentido do levantamento de espécies, que são identificadas como de florestas caducifólias ou subcaducifólias, até matas subperenes com espécies perenifólias.

\footnotetext{
${ }^{1}$ Linaldo Severino dos Santos; Helena Paula de Barros Silva; Eugênia Cristina Gonçalves Pereira; Cláudio José Cabral; Jeissy Conceição Bezerra da Silva, Departamento de Ciências Geográficas, Universidade Federal de Pernambuco, Recife-PE, Brasil

${ }^{2}$ Helena Paula de Barros Silva, Universidade de Pernambuco, PE, Brasil
} 
O estabelecimento de manchas de cerrado no semiárido nordestino se dá primordialmente devido ao fator altitude. Desta forma, essas manchas que se traduz como fragmentos, que devido ás variações na distribuição da vegetação ao longo do gradiente topográfico resultante também das relações com fatores edáficos, carecem de uma atenção especial, visando estratégias para a conservação desses remanescentes, bem como a recuperação de áreas degradadas (SANTOS et al.,2014).

O estudo do conjunto vegetacional da caatinga é necessário para se ter um panorama real de como se encontra a sua biodiversidade, como também analisar as correlações dos elementos dos diversos ambientes em que essa vegetação se estabelece. Nesse sentido, vale ressaltar que a paisagem atual é o somatório de processos históricos pelo qual ela passou sofrendo inúmeras influências, e refletindo em sua forma (CORRÊA, 2001). Alves (2007) expõe que nos últimos vinte anos (aproximadamente) $40.000 \mathrm{~km}^{2}$ foram transformados em deserto devido à interferência antrópica no semiárido nordestino, revelando que muitas áreas que eram consideradas como primárias já sofreram interferência do homem.

O termo brejos que será tratado aqui são os brejos de altitude, que se configuram como sendo áreas de exceção condicionadas por fatores naturais, caracterizadas como áreas mais amenas que as caatingas que as circundam, onde as vegetações existentes na vertente a barlavento ganham características mais úmidas, variando entre florestas caducifólias ou subcaducifólias, até matas subperenes com espécies perenifólias (LINS, 1989).

As formações vegetais do domínio cerrado sempre interessaram aos botânicos, por serem consideradas um tipo de vegetação peculiar, o que contribuiu para que vários autores conceituassem o cerrado, se destacando a seguinte:

O cerrado (ou campo cerrado, como também se diz) é a forma brasileira da formação geral chamada savana. Muitas vezes é uma savana arborizada, não poucas é uma savana arbustiva, chegando a ser um simples campo sujo, com apenas arbustos mal desenvolvidos e esparsos por cima do tapete gramináceo (RIZZINI, 1997, p.409).

Não se pode falar sobre o cerrado como sendo um bioma que obedece a padrões uniformes para a totalidade de suas manifestações, pois se trata de um conjunto vegetacional que abrange uma enorme extensão espacial, sendo o segundo maior bioma brasileiro, ficando atrás somente do bioma amazônico. Com esta enorme extensão espacial, verificam-se condições físico-naturais bastante diferenciadas em todo o seu domínio, e isto é refletido na diversidade de espécies como na estrutura da vegetação, variando de formações basicamente de gramíneas e ervas, no caso do campo limpo, às formações florestais no caso do cerradão (RIBEIRO \& WALTER, 2008). 
Para o estabelecimento de manchas de cerrado no semiárido pernambucano, e mais precisamente na área de estudo selecionada, a topografia exerce um papel extremamente condicionante, pois devido à altitude oferecida em determinados locais é possível reunir condições ambientais necessárias para que este tipo vegetacional consiga se desenvolver. As variações na declividade em determinada localidade, aliadas a outros fatores ambientais, são responsáveis pela diversidade de habitats os influenciando no gradiente de umidade, no transporte de partículas pela vertente, na organização vertical do dossel, na geração do aspecto de degrau no estrato arbóreo (GANDOLFI, 2000). Nesse sentido, a diversidade de microclimas gerados ao longo do perfil topográfico também é considerada.

\section{METODOLOGIA}

\section{1 Área de estudo}

A área selecionada para a realização da pesquisa está compreendida em áreas dos municípios de Águas Belas, Iati e Saloá, fazendo parte do Agreste Meridional de Pernambuco (figura 1). Os municípios de Águas Belas e Iati fazem parte da unidade geomorfológica depressão Interplanáltica do Alto Ipanema, enquanto o município de Saloá está assentado na Cimeira Estrutural Pernambuco-Alagoas (CORRÊA et al., 2010).

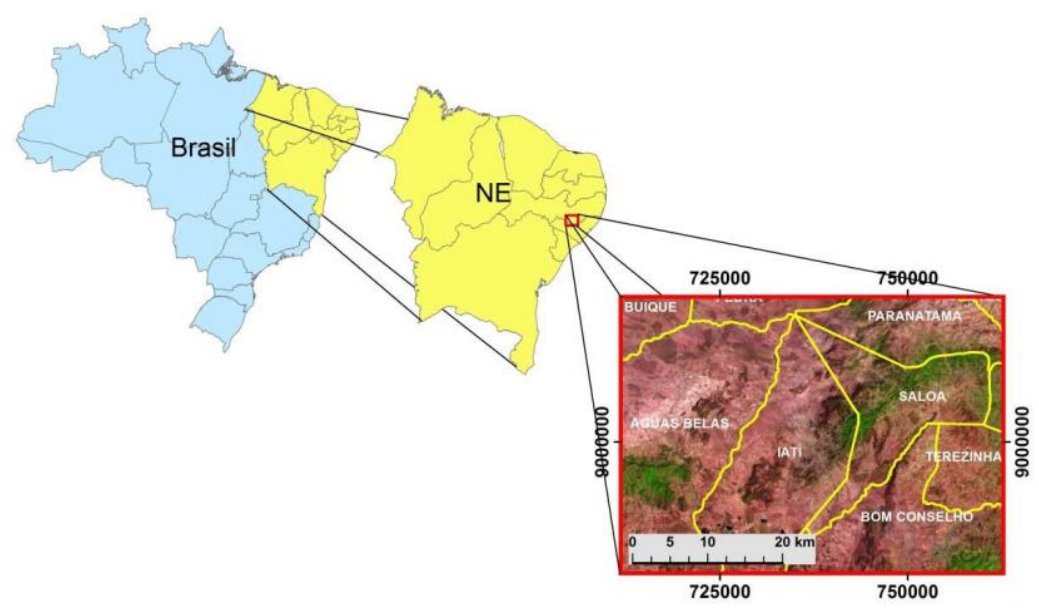

Figura 1: Localização da área de estudo, municípios de Águas Belas, Iati e Saloá, Pernambuco. Fonte: Linaldo Santos.

\subsection{Metodologia aplicada ao trabalho de campo}

Para a realização desta fase da pesquisa, foram feitas visitas a campo no mês de julho de 2013. Para tanto, o procedimento metodológico aplicado segue as recomendações do Manual Técnico da Vegetação Brasileira (IBGE, 2012). Nesse sentido, a técnica de amostragem adotada na realização da presente pesquisa foi Aleatória Restrita ou Estratificada, que consiste em 
estratificar uma determinada área florestal (população) em subpopulações homogêneas (estratos), com base na interpretação de fotografias aéreas ou outros sensores e a partir daí proceder como anteriormente. É normalmente utilizada em extensas áreas florestais como na Amazônia, ou em reflorestamentos com base na idade dos plantios, por exemplo.

Para uma melhor operacionalização dos procedimentos de campo, adotou-se uma técnica metodológica complementar, para adaptar aos objetivos e condições que a pesquisa apresentou. Tal técnica é Avaliação Ecológica Rápida (AER) (SOBREVILLA \& BATH, 1992). A utilização desta metodologia teve a função de coletar os dados qualitativos de forma rápida, embora exigindo uma analise prévia da área de estudo. O método AER se baseia em uma compreensão prévia da área da pesquisa, com base em bancos de dados, fotografias aéreas, imagens de sensoriamento remoto, mapas, para que se possa definir qual será o procedimento adotado em campo. São coletadas espécies para identificação e deposição em herbário, e características físicas da área são anotadas. Todo o processo é conduzido por formulários, previamente elaborados, facilitando a compreensão dos dados obtidos. Após esse momento, todos os dados extraídos em campo recebem tratamento, a fim de fornecer ferramentas para uma análise das informações espaciais. Estas, através da AER podem gerar, de maneira sucinta, a descrição da vegetação, realizando o georreferenciamento de manchas de vegetação, a análise do estado de conservação da área de estudo, como também da lista das espécies coletadas. Este método, considerado flexível, apresenta rapidez, facilidade de aplicação e de análise de dados, possibilitando o trabalho com uma equipe reduzida de pesquisadores.

Aliando as duas técnicas metodológicas descritas no recorte espacial selecionado para a realização da pesquisa foram instaladas dez parcelas com tamanho de $30 \mathrm{~m}$ x $30 \mathrm{~m}$. Estas parcelas foram alocadas ao passo que havia mudanças significativas na composição da vegetação, como também no gradiente topográfico. Ressalta-se também que, procurou-se instalar as parcelas nos locais onde apresentava sua vegetação minimamente preservada. Deste modo, obedecendo a estes requisitos, não houve equidistância entre as parcelas, importando para a pesquisa as nuances encontradas ao longo do perfil de paisagem. As parcelas foram distribuídas com a finalidade de realizar coletas botânicas, feitas de modo a contemplar as espécies dominantes em cada ambiente selecionado. Após as coletas, os espécimes foram levados para herbário a fim de identificá-los e depositá-los, com o objetivo de validar a hipótese da variação da estrutura da vegetação ao longo do perfil topográfico, como também da ocorrência da mancha de cerrado no topo deste perfil. Além disso, foi feito registro fotográfico para distinção de fisionomias vegetais, e georreferenciamento dos locais de coleta com uso de receptor GPS. 


\section{3 Índice de vegetação por diferença normalizada (NDVI)}

O NDVI é simples, fácil de ser implementado e pode ser efetivo na predição de propriedades da superfície quando a copa da vegetação não é muito densa ou muito esparsa, pois, se a copa for muito esparsa, o sinal do solo (ou outra feição) interferirá no NDVI e, por outro lado, se a copa for muito densa, a reflectância no vermelho não altera muito, mas, no infravermelho próximo, continua a aumentar, saturando o NDVI (LIANG, 2004). Torna-se assim, insensível, ou saturado, para valores de IAF (Índice de Área Foliar) de 3 a 4, que está abaixo da média global das florestas tropicais (média de 4,7) (ASNER et al., 2004).

O NDVI é obtido através da equação:

$$
N D V I=\frac{(N I R-R)}{(N I R+R)}
$$

Em que: NIR e R são fatores de reflectância bidirecional espectrais (razão da radiância do alvo na superfície pela radiância de uma superfície conservativa, lambertiana) nos comprimentos de onda do visível (vermelho) e infravermelho próximo, respectivamente (MYNENI et al., 1995). São as reflectâncias da superfície no infravermelho próximo $(0,8 \mu \mathrm{m}$ a $1,1 \mu \mathrm{m})$ e no visível (vermelho $-0,6 \mu \mathrm{m}$ a $0,7 \mu \mathrm{m})$ (ASRAR et al., 1984).

\subsection{Procedimentos Realizados na Construção do Perfil de Paisagem}

O perfil do relevo foi traçado utilizando o software Google Earth, através das ferramentas contidas no menu Perfil de Elevação. Após este passo, o perfil de relevo foi removido e transportado para o software PowerPoint do Pacote Office do Windows, neste ambiente foi possível agregar as outras informações, como também inserir as fotografias da área. $\mathrm{O}$ índice de aridez foi definido usando seguinte equação, P/ETP (Precipitação/Evapotranspiração Potencial), em que a ETP foi estimada utilizando o sottware BHnorm 4.0. Os dados foram obtidos do banco de dados do Departamento de Ciências Atmosféricas (DCA) da Universidade Federal de Campina Grande.

\section{RESULTADOS E DISCUSSÃO}

3.1 Relação do NDVI (Normalized Difference Vegetation Index) com os valores altimétricos do terreno 
Uma análise bastante pertinente é a interpretação dos valores de densidade da vegetação obtidos a partir do NDVI, confrontados com os valores altimétricos do terreno. A figura 2 demonstra a variação de altitude que vai de $391 \mathrm{~m}$ na parcela 4 a sua maior altitude 1090 metros na parcela 9. O gráfico evidencia também o comportamento do NDVI, onde seu menor valor foi na parcela 5 com um valor de 0,18. Já a parcela que marcou o maior valor para o NDVI foi à de número 8, registrando 0,49 para este índice. Através desta figura, também é possível notar que a linha do NDVI acompanha os valores altimétricos dos segmentos da área estudada, salvo algumas exceções como as parcelas 5 e 9. Que ocorreu, provavelmente, devido à existência de clarões deixando o solo exposto, motivo pelo qual faz com que o valor do NDVI diminua.

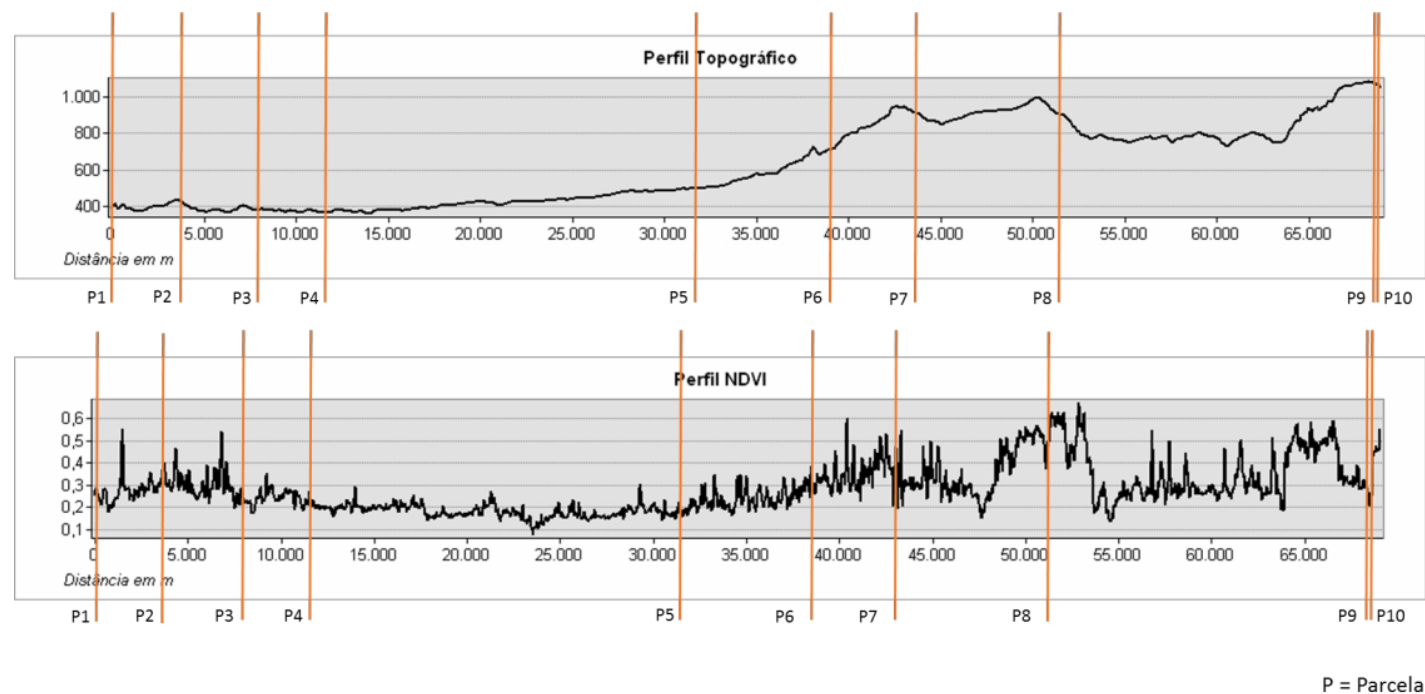

Figura 2: Perfis topográfico e de NDVI, mostrando o comportamento da altitude e do índice de vegetação ao longo da área de estudo, situada nos municípios de Águas Belas, Iatí e Saloá, Agreste Meridional de Pernambuco. Em detalhe as marcações das parcelas.

Fonte: Linaldo Santos.

\subsection{Perfil de paisagem entre os municípios de Águas Belas e Saloá}

$\mathrm{O}$ presente estudo se torna mais abrangente e esclarecedor à medida em que o recorte espacial proposto é analisado traçando um panorama fisiográfico do recorte da paisagem, abrangente aspectos das unidades de relevo, dos solos, e das diferentes coberturas vegetais envolvidas nesse processo de diferenciação da vegetação ao longo do perfil topográfico, como pode ser visualizado na figura 3, que expõe os diferentes aspectos ambientais da área estudada. 


\section{Perfil de Paisagem entre Águas Belas e Saloá}

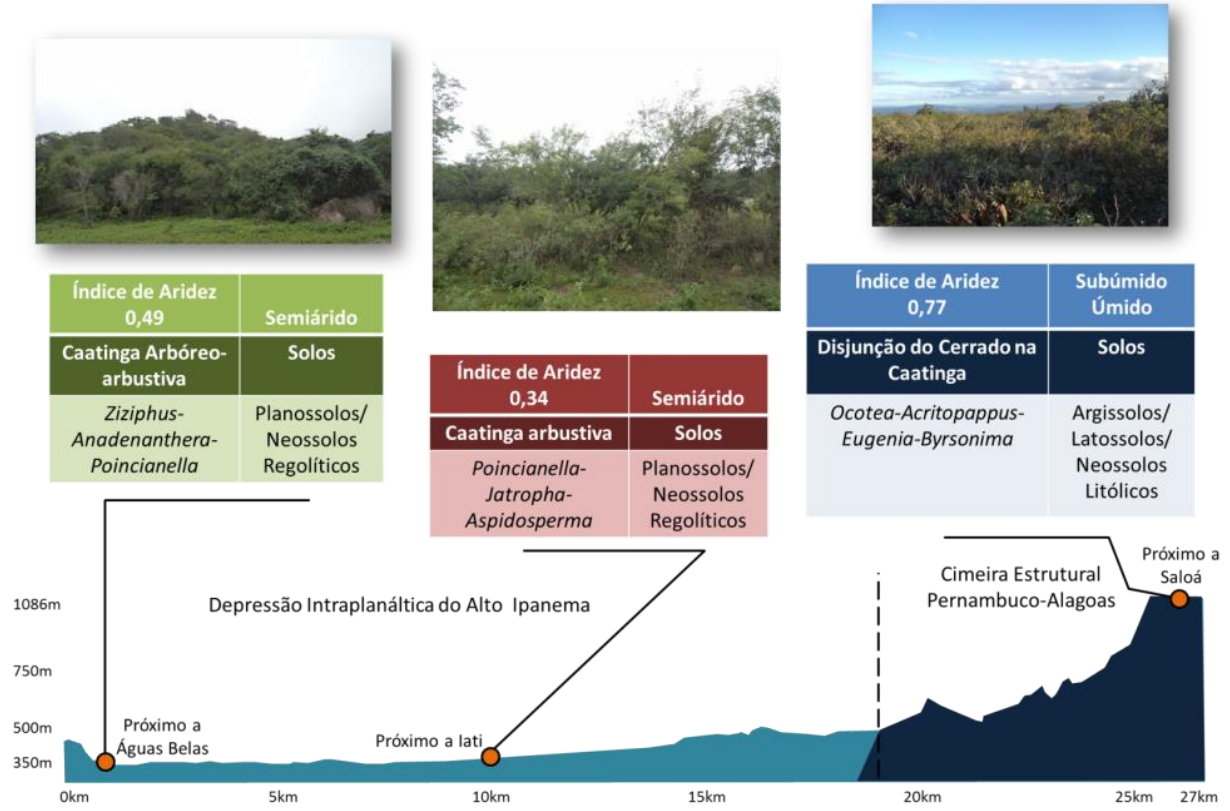

Figura 3: Perfil da Paisagem entre Águas Belas e Saloá

Fonte: Linaldo Santos.

Assim, através de agrupamentos das características ambientais, tais como: tipos de vegetação, índice de aridez, tipos de solo e unidades de relevo, foi possível estabelecer um perfil esquemático de como as diferentes formações vegetais se distribuem ao longo do gradiente topográfico.

De acordo com Thornthwaite (1948), o índice de aridez se dá numa relação da quantidade de pluviometria $(\mathrm{P})$, e da perda máxima possível de água por Evapotranspiração Potencial (ETP). A variação das classes de índice de aridez que se reflete nas alterações dos ambientes pode ser constatada através da tabela 1 .

Tabela 1: Classificação do índice de aridez de Thornthwaite. Fonte: Autor

\begin{tabular}{ll}
\hline \multicolumn{1}{c}{ CLIMA } & \multicolumn{1}{c}{ ÍNDICE } \\
\hline Hiper-árido & $<\mathbf{0 , 0 5}$ \\
Árido & $\mathbf{0 , 0 5}-\mathbf{0 , 2 0}$ \\
Semiárido & $\mathbf{0 , 2 1}-\mathbf{0 , 5 0}$ \\
Sub-úmido seco & $\mathbf{0 , 5 1 - 0 , 6 5}$ \\
Sub-úmido e úmido & $>\mathbf{0 , 6 5}$ \\
\hline
\end{tabular}


Com relação à aplicação do índice de aridez ao presente estudo, exposto na figura 3 , este foi de 0,34 nos ambientes onde as condições fisiográficas são mais secas, apresentando uma vegetação típica de caatinga arbustiva. Nos locais onde se estabelece uma caatinga arbórea o índice de aridez ficou em torno de 0,49 , portanto apresentando condições mais úmidas, contudo permanecendo sob o domínio semiárido. Nas parcelas alocadas no topo do brejo, as condições de umidade são bastante significativas, refletindo no índice de aridez, que ficou em torno de 0,77, estando este ambiente sob o domínio do clima subúmido tendendo a úmido, fato este que favorece o estabelecimento do enclave de cerrado na área.

Desta forma, tais formações vegetais variam desde a caatinga típica de ambientes secos, passando por ambientes onde os condicionantes físicos favorecem o desenvolvimento de mata serrana, e culminando no enclave de cerrado no topo do Brejo de Saloá.

\section{CONSIDERAÇÕES FINAIS}

Os resultados alcançados na presente pesquisa, apontam que na área selecionada ocorre uma marcante variação na estrutura da cobertura vegetal. Tal variação é propiciada pelos condicionantes ambientais, destacando-se o gradiente topográfico. Desta forma, apresenta ambientes de caatinga típica, no setor da Depressão Interplanáltica do Alto Ipanema, nos municípios de Águas Belas e Iati, passando por ambientes úmidos na Cimeira Estrutural Pernambuco-Alagoas, onde está inserido o município de Saloá, onde se desenvolve uma vegetação mais densa e de maior porte, como a mata serrana.

Através da identificação em herbário das coletas de material botânico, foi constada uma disjunção de cerrado inserida na Cimeira Estrutural Pernambuco-Alagoas, no topo do brejo em Saloá, tornando a paisagem mais peculiar, inclusive no sentido da diversidade de habitats.

Os valores obtidos na análise do Índice de Vegetação por Diferença Normalizada (NDVI), em confronto com as cotas altimétricas, demonstraram que ocorre uma relação entre esses dois parâmetros, sendo verificado que a densidade da vegetação aumentou à medida que os valores do NDVI e da altitude também aumentava.

É importante salientar, nesta pesquisa que evidencia a variação da cobertura vegetal em um perfil de paisagem, a relevância para a Geografia e mais precisamente para a Biogeografia, inclusive no âmbito do planejamento ambiental e conservação de ecossistemas ameaçados. 


\section{REFERÊNCIAS}

ALVES, J.J.A. Geoecologia da caatinga no semiárido do Nordeste brasileiro. Rev. Climatologia e Estudos da Paisagem, 2007, v.2, n.1, p. 58-71.

ASNER, G. P., NEPSTAD, D., CARDINOT, G., RAY, D. Drought stress and carbon uptake in an Amazon forest measured with spaceborne imaging spectroscopy. PNAS, 2004, v. 101, n. 16, pp. 6039-6044.

ASRAR, G., FUCHS M., KANEMASU, E. T., HATFIELD, J. L. Estimating absorbed photosynthetic radiation and leaf area index from spectral reflectance in wheat. Agronomy Journal, 1984, v. 76, pp. 300-306.

CORRÊA, A.C.B. Dinâmica goemorgológica dos compartimentos elevados do Planalto da Borborema, Nordeste do Brasi. Rio Claro. Tese de Doutorado- IGCE, UNESP. 2001,386p. CORRÊA, A. C. B., TAVARES, B. A. C., MONTEIRO, K. A., CAVAlCANTI, L. C. S., LIRA, D. R. Megageomorfologia e Morfoestruturas do Planalto da Borborema. Revista do Instituto Geológico, 2010, n31. São Paulo. p.35-52.

GANDOLFI, S. Historia natural de uma floresta estacional semidecidual no município de Campinas (São Paulo, Brasil). 2000. 520 f. Tese (Doutorado em BiologiaVegetal) Universidade Estadual de Campinas, Campinas, 2000, 551p.

IBGE. Manual técnico da vegetação brasileira: sistema fitogeográfico, inventário das formações florestais e campestres, técnicas e manejo de coleções botânicas, procedimentos para mapeamentos. 2a ed. IBGE-Instituto Brasileiro de Geografia e Estatística, Rio de Janeiro, 2012, 275p.

LIANG, S. Quantitative remote sensing of land surfaces, ed. Wiley Interscience, New Jersey, USA, 2004, 534p.

LINS, C.R. As Áreas de Exceção do Agreste de Pernambuco. SUDENE/PSU/SER. Série estudos Regionais. 1989, Recife, 402p.

MYNENI, R. B., HALL, F. G., SELlERS, P. J., MARSHAK, A. L. The interpretation of spectral vegetation indexes. IEEE Transactions on Geoscience and Remote Sensing, 1995, v. 33, pp. $481-486$.

RIBEIRO, J.F. \& WALTER, B.M.T. As principais fitofisionomias do bioma cerrado. In: SANO, S.M., ALMEIDA, S.P de. (Ed.) Cerrado: ambiente e flora. Brasília: EMBRAPA, 2008, v.1, p.152-212.

RIZZINI, C. T. Tratado de fitogeografia do Brasil - Aspectos ecológicos. São Paulo:Hucitec, Edusp. $2^{\text {o }}$ volume, 1997. 747p. 
SANTOS, L. S.; SILVA, H. P. B; PEREIRA, E. C. G. Cerrado em área disjunta em brejo de altitude no agreste pernambucano, brasil. Boletim Goiano de Geografia. 2014, v.34, n.32, p.337353.

SOBREVILLA, C. \& BATH, P. Evaluación ecológica rápida: un manual para usuarios deAmérica Latina y el Caribe. Washington, The Nature Conservancy. 1992.

THORNTHWAITE, C. W. An approach toward a rational classification of climate. Geographical Review, New York, 1948, v. 38, p. 55-94.

Recebido em: 14/08/2016

Aceito para publicação em: 01/10/2016 